\title{
Practices of Open and Distance Education in Nepal : Opportunities and Challenges
}

\author{
Arjun Neupane \\ arjun.neupane@tucded.edu.np \\ Lecturer \\ Central Department of Education, T.U., Kirtipur
}

\begin{abstract}
The purpose of this study was to explore the opportunities and challenges of open and distance learning $(O D L)$ system and to explore the gateway for the implementation of $O D L$ to optimizing the opportunities in policy and implementation in higher education of Nepal. To achieve the goal, explanatory sequential research design was used. Questionnaire form and interview schedule were the tools of the study. The findings revealed that students have positive perceptions towards the use of open and distance learning mode. The benefits accruing from technology usage include: improved access, interaction with teachers as well as others tu dents, access to a wide variety of recent and updated resources that are available online as well as contents ha ring. Challenges faced by both the teachers and the learners were unreliable internet accesses, techno phobia and inadequate pedagogical skills of online teachers. Some of the challenges are academic, some are administrative and some others are Information and Communication Technology (ICT) related. It is suggested that online friendly curriculum has to be developed for ODL mode that must be focused on the ICT integration in the subject areas.
\end{abstract}

Keywords : Open and distance education, ICT integrated pedagogy, distance education, online education

\section{Introduction}

The open and distance education system adopts a flexible approach in respect of content selection, pace and place of the body in an ever updating manifestation of modern communication technology. The distance mode allows the educational system to be open and flexible. The new policy of Tribhuvan University (TU) also emphasized the importance/ necessity of the open and distance education system in the higher education. Moreover, the policy of TU has to run all the programme of the university in the dual mode viz. face-to-face and open and distance mode. Open and distance learning (ODL) is now becoming significant all around the world in contemporary educational development as an alternative way to meet the huge unmet demand for education at all levels and especially for higher education. The main objective of ODL is to reach the unreached and provide education at the doorstep of the learners and according to their convenience. 
Enrolment and success rates in higher education are relatively low,even for the face-to-face mode of study (Neupane, 2018a ). The situation is worse for distance and online modes. At the same time, distance and online learning is becoming progressively more popular with higher learning institutions across the world. In order to increase enrolment in undergraduate mathematics and to boost success rate sat ODL institutions, a clear understanding of the needs of distance and online mathematics students is required. Reju (2016) added that it was important to understand their current experiences with four elements of provision: instructional delivery, assessment procedures, learning facilitation and support services.

The opportunity created by online based learning would be guaranteed only when there is an environment of e-learning in every place and every time. Most of the regions of our country are behind the access of internet. Load shedding is another major problem in our country. Online based learning needs regular contact to the teacher and students lying in the remote area. An inadequate or unreliable communications systems; limited access for the population at large to electrical and electronic communications technologies; lack of qualified teaching, media production and administrative personnel are the pertinent problems in executing the programme. In this context, I have attempted to identify the opportunities and challenges of open and distance learning system and to explore the gate way for the implementation of ODL in education stream of TU, Nepal.

\section{Methodology}

Explanatory sequential research design (Creswell, 2014) was used in the study. Constituent campuses and Open and Distance Education Center (ODEC) of Tribhuvan University where the open and distance learning program is running under Faculty of Education, Tribhuvan University (TU) were the study site in this research work. This is the first hand experience of the faculty members of these institutions and officials of the Faculty of Education, TU. Only two campuses, one from Kathmandu valley and one from outside of valley, and ODEC were chosen for this study by using purposive sampling techniques. All the faculty members and students of these campuses were the sample of the study. And two administrative staff and four faculties having experiences to run distance learning of Faculty of Education were chosen for interview.

Close-ended questionnaire and interview guidelines were the research instruments to collect information with faculty, officials and students. Questionnaires were developed with the help of different international reports and researches related to ODL. The reliability and validity of the questionnaire were established by piloting the tools to the ODEC students. In- depth interview was conducted with four online faculties. Moodle documents were used as the online document in this study. Descriptive statistics was used in the analysis of the quantitative data. The collected data were analyzed using general inductive approach.

\section{Results}

The result of the study using quantitative and qualitative data has been presented in this part. Chi-square test was used to test the significance of the statements using inferential statistics. Opportunities and challenges of ODL were analyzed descriptively. Opportunities related to the 
students' experiences, support services provided by office and ODL system were analyzed in separate heading. Internet related challenges and learning related challenges were analyzed using inferential statistics. To analyze the causes of ODL effectiveness, result of the study has been drawn using the interview data and FGD with students. To analyze the causes, thematic analysis was used.

\section{Opportunities and Challenging Factors}

ODL is a new and challenging practice for TU. It runs the ODL programmes in different modes in Masters of Education (M. Ed.) and Bachelor of Education (B. Ed.) level. ODEC runs the ODL program in Mathematics and English Education since 2015. ODEC has around fifty students studying M. Ed. level. Faculty of Education (FoE), Dean Office runs the ODL program in M. Ed. and B. Ed. level in seven constituent campuses. ODEC runs M. Ed. programs using ODL mode in two subjects i.e. Mathematics Education and English Education.

Reflection of ODL practices. ODL students and faculties were very excited in studying through the online mode. . Students have got the great opportunities to develop the qualification and professional carrier one at a time. Research article published from ERIC indicates that the ODL system has very highly useful and more practices mode of learning in the Western Europe. Moreover, student centered Learning Management System (LMS) is the beauty of ODL system. The survey responses about the practice of ODL including statements and inferential test were categorized in the table below.

Table 1: Practice of Students and Tutors about ODL

\begin{tabular}{|c|c|c|}
\hline Subjects & $\begin{array}{l}\text { Chi-Square } \\
\text { value }\end{array}$ & $\begin{array}{l}\text { Asymp. } \\
\text { Sig. }\end{array}$ \\
\hline Overall satisfaction with ODL System & $19.000 * *$ & .001 \\
\hline Overall satisfaction with LMS used & $13.000 * *$ & .011 \\
\hline $\begin{array}{l}\text { The objectives of ODL and online are clearly made known by my } \\
\text { tutor. }\end{array}$ & 7.000 & .136 \\
\hline ODL is difficult because I do not understand it. & $13.778 * *$ & .008 \\
\hline $\begin{array}{l}\text { Learning of mathematics through ODL mode is mode in my } \\
\text { institution is frustrating. }\end{array}$ & 7.000 & .136 \\
\hline $\begin{array}{l}\text { Many problems cannot be solved through distance and online } \\
\text { learning. }\end{array}$ & 7.000 & .136 \\
\hline I enjoy learning through ODL. & $12.000 * *$ & .017 \\
\hline Learning through ODL mode saves time and effort for learners. & $11.000 * *$ & .027 \\
\hline I have reliable access to internet for my school /institutional needs. & 9.000 & .061 \\
\hline The course materials are well developed for learning in ODL. & 7.000 & .136 \\
\hline The course materials are sufficient for learning. & $13.000 * *$ & .011 \\
\hline $\begin{array}{l}\text { The course materials challenge and arouse my curiosity to learn new } \\
\text { concepts. }\end{array}$ & $11.000 * *$ & .027 \\
\hline $\begin{array}{l}\text { The course materials challenge and arouse my curiosity to learn } \\
\text { difficult concepts. }\end{array}$ & $17.000 * *$ & .002 \\
\hline
\end{tabular}


The abstract nature of courses is not simplified in the design of the course materials.

I have access to course materials online over the internet.

$13.000 * * \quad .011$

The contents covered in the course materials are quite adequate for the period the student is required to complete the course work.

$24.000 * *$

8.000

ODL course materials in my institution meet students' mathematical and experiential needs for:

Skill Development

$15.000 * * \quad .005$

7.000

.136

Requirements for degree award and certification.

9.000

.061

I usually feel so bored when I study subject concepts that I quit before I finish what I planned to cover in the course material.

4.000

When the course material is difficult to understand, I give up or study only the easier parts.

$3.000 \quad .558$

The course materials are fairly interactive to understand.

1.000

Even when the course materials are not interactive enough, I manage to continue working to understand and finish them.

The following can help to further improve the students' experiences in ODL in my institution: i) Access to efficient

ii) Access to my tutors

7.000

iii)Flexible teaching and learning

$11.000^{* *}$

iv) Use different medias

Distance and online learning gives access to enough resources

to learn at my university.

Face-to-face remains the dominant method of teaching and learning of in institution.

Table 1 indicates that students and tutors of ODL mode were very excited in teaching and learning (19.0). Students were able to solve their problems by using ODL mode and using internet. They could observe the tutors responses at home and their free time. Students were confused to operate the ODL mode like moodle, e-mail, internet and facebook chat. Later on the software were helpful for learning. Additional course materials helped to the students to learn smoothly. Limited time and internet facilities were the barriers to run ODL programme effectively.

Not reliable access of internet services (9.0) was provided to fulfill the need for the ODL students. The level of curiosity of students for new concepts was found better (11.00). This indicates that the curiosity of students is high to learn new contents using ODL mode. Difficult contents also became effective (17.00) using ODL mode. But, abstract concepts of mathematical expressions felt difficulty using ODL system (Neupane, 2018a).

Flexible learning, equal opportunities, open in terms of place and time, development of skilled educators, inclusive educational attainment, addressing the slogan of higher education for 
all were significantly effective opportunities of ODL. Internet access, assessment and output evaluation were the major challenges to run ODL programme.

Students' problem solving environment, open in terms of space, flexible in terms of time, enjoyable learning environment, saving time and efforts, access for LMS, familiar with recent tools and techniques were the opportunities of ODL mode. Internet related challenge was reliable access of internet for students and tutors. It is very difficult to provide the internet facilities for students in their institutions or their home. Customization of interactive courses and development of materials were the major learning challenges in our ODL practice and the out put of data.

ODL experiences with facilitation and assessment. ODL system is a newly practicing concept in Nepal. It is better for those who cannot get the opportunity for the face- to-face mode. Major responses about facilities and assessment system are listed (Table 2) and explained in the following paragraphs.

Table 2: Students' experiences with ODL Facilitation and Assessment Reflection

\begin{tabular}{|c|c|c|}
\hline Students' Experiences with assessment ODL environment & $\begin{array}{l}\text { Chi-Square } \\
\text { value }\end{array}$ & $\begin{array}{l}\text { Asymp. } \\
\text { Sig. }\end{array}$ \\
\hline $\begin{array}{l}\text { Assessment procedures are well specified and included in the design } \\
\text { of course materials in my institution }\end{array}$ & 4.889 & .299 \\
\hline $\begin{array}{l}\text { There are no adequate resources to support student assessment } \\
\text { procedures. }\end{array}$ & 5.000 & .287 \\
\hline $\begin{array}{l}\text { The guiding principle on assessment is not well understood by the } \\
\text { students. }\end{array}$ & 4.000 & .406 \\
\hline $\begin{array}{l}\text { The students' assessment guidelines involve traditional method of } \\
\text { assessment than ODL activities. }\end{array}$ & 7.000 & .136 \\
\hline $\begin{array}{l}\text { Online assessment of students is the only form of assessment } \\
\text { procedure used in my institution. }\end{array}$ & $13.000 * *$ & .011 \\
\hline $\begin{array}{l}\text { My institution makes use of both online and traditional assessment } \\
\text { procedures in assessing the ODL learners. }\end{array}$ & 7.000 & .136 \\
\hline I prefer traditional method of assessment than online assessment. & $9.000^{\mathrm{b}}$ & .061 \\
\hline $\begin{array}{l}\text { It is better to use both online and traditional procedures to } \\
\text { assess ODL students. }\end{array}$ & $13.000 * *$ & .011 \\
\hline $\begin{array}{l}\text { Access to assessment procedures in my institution's ODL platform is } \\
\text { very easy. }\end{array}$ & 8.000 & .092 \\
\hline I enjoy doing assessment on online. & 7.000 & .136 \\
\hline Assessment feedback is promptly obtained online. & 7.000 & .136 \\
\hline $\begin{array}{l}\text { Distance and online assessment procedures in my institution are very } \\
\text { effective. }\end{array}$ & 8.000 & .092 \\
\hline \multicolumn{3}{|l|}{ Students' experiences with ODL facilitation } \\
\hline $\begin{array}{l}\text { I work with other students from my university to complete course } \\
\text { assignments. }\end{array}$ & 5.000 & .287 \\
\hline $\begin{array}{l}\text { I prefer setting aside time to discuss course materials with a group of } \\
\text { mathematics students in my school. }\end{array}$ & $11.000 * *$ & .027 \\
\hline
\end{tabular}


I work together with my instructor to clarify the difficult concepts .

$17.000 * * \quad .002$

When I have difficulty in learning concepts in my school, I try to

$24.000 * * \quad .000$

remain a self-learner without obtaining help from anyone.

Collaborative activities with other students help to improve my $\quad 12.000 * * \quad .017$

performance in my subject.

Online collaboration is very effective in my school and it fosters $\quad 4.889 \quad \begin{array}{ll}\text { 299 }\end{array}$

learning.

I have opportunity to experience academic collaborative activities with $13.000^{* *} \quad .011$

other ODL students in other institutions such as:
i) Online collaboration
$13.778 * * \quad .008$
ii) face to face collaboration
$8.000 \quad .092$
iii) sharing
$11.000^{* *}$

The chi square value of assessment procedures are well specified and included in the design of course materials is 4.88 in ODL system. Lack of ICT integrated pedagogy in moodleplat form; students' assessment does not support for the course materials effectively. There were not adequate resources and materials to support the students' assessment in ODL system (5.00). Online system of assessment used only for formative evaluation (13.00) in ODL system. Students were not feeling enjoyable doing online assessment (7.00).

Students' online collaboration had significant role in the ODL system (13.78).However, collaboration between students and tutors was not significantly effective. Face-to-face collaboration and experience sharing in the contact session was effective.

Enjoyable internal assessment, online surfing for assessment, and skill development in the learning, computer collaboration, interaction between students and student and tutors were the opportunities of ODL in the assessment practices. Online familiar on LMS platform and online sharing were the internet challenges for assessment and facilities in ODL system. Continuous assessment system, online feedback, adequate resources for assessment and facilities were the challenges for ODL system.

Influence of technological support services. Successful ODL system is depending up on the technological supports and competencies of tutors and learners in education. Students' responses about the technical support for ODL mode with their significance have been presented in table 3 .

Table 3: Technological Influence in $O D L$

\begin{tabular}{|c|c|c|}
\hline $\begin{array}{l}\text { The technologies that influence support services in ODL } \\
\text { learning }\end{array}$ & Chi-Square value & Asymp. Sig. \\
\hline $\begin{array}{l}\text { Support services are provided only during the working hours } \\
\text { of the week. }\end{array}$ & $11.000 * *$ & .027 \\
\hline The following media are used to support mathematics: & 6.000 & .199 \\
\hline i) Internet & 4.000 & .406 \\
\hline
\end{tabular}




\begin{tabular}{lll} 
ii) Audio visual & 7.000 & .136 \\
iii) Intranet & 4.000 & .406 \\
iv) Printed Materials & 8.222 & .084 \\
v) CD/Dvd & 6.000 & .199 \\
vi) Radio Lessions & 4.889 & .299 \\
vii) TV & 8.000 & .092 \\
i) E-mail & 8.000 & .092 \\
ii) Talephone & $11.000^{* *}$ & .027 \\
iii) Chat & 8.000 & .092 \\
iv) One side Tuter & 7.000 & .136 \\
v) Mobile sms & $12.000^{* *}$ & .017 \\
vi) LMS & $13.000^{* *}$ & .011 \\
vii) Feedback & 8.000 & .092 \\
There are sufficient library resources for ODL & 7.000 & .136 \\
There are sufficient library resources for mathematics & 8.000 & .092 \\
There are accessible library resources for & 8.000 & .092 \\
I am able to access the library resources online from & $12.000^{* *}$ & .017 \\
My institution provides access to career counseling & 4.000 & .406 \\
\hline
\end{tabular}

Students were not resourceful for the ODL system. Fifty percent of total students used mobile internet for ODL. Students used moodle, e-mail, telephone, facebook and blog for the ODL. Eighty percentages of students submitted their assignment in moodle and other used e-mail and facebook massager as well. Adequate resources and tutors competency does not fulfill the need to support student assessment procedure. Assessment feedback system (8.00) is not fully supportive. It needs to respond quickly as far as possible.

Learning by self-efforts, self-practice space, collaborative learning were the opportunities for the ODL learners. Computer collaboration and mobile effectiveness were the major challenges of technologies and support services. Resources materials, ICT tools and techniques, operating skills to the tutors and students were the major challenges of ODL system.

\section{Analyzing the Causes}

ODL system is one of the best modes of learning for those who does not attained in the face to face mode for higher education. Family background, economic condition, social acceptance, unequal distribution of technological resources and access to grab the opportunities are the major factors to get the higher degree in Nepal (Neupane, 2018b). Educators expected that the ODL modes of learning address these people. I would like to analyze the interview and FGD data about the causes of opportunities and challenges of implementation of ODL in Nepali context.

Enhancing Interactions and Collaborations. In online education, there are presently a number of technologies and instructional activities used to promote course interactions. Frequently used 
technologies in online courses include textbooks, multimedia that combines text, images, and audio either through Internet, streaming audio and video, and synchronous and asynchronous communication tools, such as discussion boards, instant messaging, and voice chatting, and filesharing. The availability of these technologies does not necessarily mean that they are present in every online course. In addition, the choice of technologies used in online courses is more often decided by economic, technical, or even political motives rather than pedagogical rationales (Bonk (1998). Learners' were motivated to online class using Moodle platform.

Reading and logical reasoning were the major problem and challenge in ODL mode of learning for the abstract concepts in Mathematics and English students. Learners felt the difficulty to conceptualize the new terms, terminologies and symbols of abstract body of knowledge. It is also challenges to implementation in online learning. Learner's opinion has presented below about the need and importance of online or virtual presence of teachers for online education.

Effective institutional delivery system for ODL mode is video conference and virtual class. Discussion forum helps to share our opinion about the common logical phenomenon related to our discipline.

ODL practitioners and researchers have always been concerned with how much interactivity a distance course could provide for students, since interaction is considered a necessary ingredient for a successful learning experience (Moore\& Tait, 2002). Above opinion of student indicated that effectiveness of ODL depends upon the interaction and online integration with subjective knowledge.

Open and distance learning is open for time and place. I can learn at any time, at anywhere and anytime repetition. If we have internet facilities then we can easily available the opportunity for ODL. We can use the different online tools and techniques from ODL mode.

Teachers feels easily address their work in ODL activities and facilities for providing the course materials easily. Major problem was the facilities of using internet and their qualities.

Nevertheless, it is second-generation Web tools that promise to take inter activity to the next level. Blogs (Weblogs), wikis, and podcasts can be implemented alone or in conjunction with other applications such to create engaging learning environments.

Teachers, as well as students, currently use blogs to boost the learning experience; some blogs are student-controlled while others are instructor-managed.

Tutors have described some of the dimensions that comprise the concept of interaction, such as communication, collaboration, and active learning. Frequently the social process was highlighted in definitions. Additionally, interaction in Web-based courses can occur synchronously or asynchronously.Interaction and computer collaboration between the students was effective than 
the interaction between tutors and students. Poor feedback system indicated that online meeting has an important role in ODL mode.

Academic Challenges. Academic excellence is the major quality for the successful academic program. There are different academic challenges for implementation of ODL in Nepal. The major challenges of the effective implementation of ODL system has described below.

Acceptability of ODL System for general public. The concept of ODL system is still at the budding stage for the online students. It is comparatively a new concept for the general public. The first and foremostaim of the ODL institutions is to make the general publica ware and establish a thrust on this concept of Open and Distance Learning. The acceptability of this mode of education is very essential for the people as this mode is designed for the benefit of the general masses. The acceptance may increase the public awareness of the need and lucidity of education through distance mode, which is still far cry from common level.

Final examination must be provided using ODL mode. Otherwise, we have to provide the opportunities for final examination through the near constituent campus of TU.

There is a dilemma about the examination system in ODL mode. Because of the ODL system, we must be provided the online evaluation system. Although, from the side of examination it is sensitive case, it is very difficult to do so in Nepal. Therefore it is a challenge for ODL system till now.

Quality Assurance in $\mathbf{O D L}$ system. Maintaining quality is the major challenge forth eo pen and distance institutes. The National Kn Commission opinions on the importance of quality, “... the biggest challenge faced in higher education, therefore, is the provision of quality higher education to the greatest number, at the lowest possible cost to the learner". And it is more challenging for the open and distance learning.

People do not believe on the ODL system in Nepal because they do not believe on the quality of education using ODL mode of learning in M Ed level. We are unable to revise the online friendly mode of curriculum and ICT friendly teaching environment. We are just using the annual course in semester system and in the online mode as well.

For quality assurance through distance mode, the National Knowledge Commission (NKC) recommended the constitution of an External Quality Assurance Cell to assess and evaluate the ODL institutions at regular interval. Distance Education Council (DEC) also decided to have a Centre for Internal Quality Assurance (CIQA) in all open universities of the country.

Self-learning materials (SLM) both in printed and audio-visual forms are the heart and soul of ODL system and they should be of high quality. 
Adequate and effective counselling sessions should be provided through face to face form as well as through audio-visual form by using information and communication technology (ICT).

Timely and adequate learners support services should be provided for success of ODL system.(S)

Quality of ODL has felt to improve the quality of education. There is the lack of sufficient information about ODL and enough counseling to the students, the effectiveness and quality of ODL does not rise in Nepal.

Non acquaintance with ICT in remote areas of Nepal. The concept of ICT is totally new in the entire region. Literacy, economical backwardness as well as proper transportation and communication are a few major considerable factors in this regard.

Lack of internet in the remote area of Nepal, we have very difficult to operate moodle and other learning management system and internet facilitated system.

Nepal is a beautiful country and has different geographical structures. We live in developing country, Nepal. Without developing the internet facilities, ODL system does not unifies in the stream of ODL mode.

Administrative challenges. There are a few challenges at the administration part of the universities. It varies from the different universities and open universities to the dual mode universities like TU. The following are the common challenges faced in administration level.

Human resource and infrastructure. The creation of the online infrastructure for running the affairs oft he institutions is the first and foremost challenge for ODL. The working out of the need sinterms of human resource and infrastructure for creating an administrative setup is difficult for the reason that there is no model to follow in the state level.

Lack of support services provider, I have facing the difficulty to operate the software provided in the ODL mode. First of all, I felt difficult to upload assignment in due date because I forget to do it. If there is a supporter in the office, I did that easily.

It is not easy to convince the people who matters for providing necessary human resource and infrastructure, because the system of ODL has not yet been easily comprehensive to the people by and large. The concept of open and distance learning System is a keen to correspondence education for which a skeleton administrative setup is sufficient.

ODL system is better for the low achievers and job holders in higher education in Nepal. It is the alternative mode of private study. 
Some times attitude of the authorities of the dual mode universities towards the distance education is not favorable and still they believe that it is the second category learning system in their own institution.

Evaluation related challenges. Evaluation of the learners in ODL is not traditional or formal like other universities. It is observed that in a few institutions, the examination and evaluation are very flexible resulting high rate of pass percentage, which may not be expected from a group of distance learners.

Final evaluation system is also in the ODL mode. TU authorities must be developed online examination system. We are facing difficulty in central examination system.

Students raised major issue about the central examination system in ODEC. All the studentshave appeared in the center provided by FoE, Dean Office till now. Examination system is a bit sensitive and the lack of infrastructure and fully online structure examination system was not in ODL mode. It is necessary to make online examination system in the future as far as possible.

ICT related challenges. There is a shortage of technical manpower to keep tract of each and every learner who is appearing in the examination in his or her own pace. At the time of preparation of the audio and audio- visual study materials the first and fore most concern is the need of the learners of the ODL. While doing the survey several aspects have come up.

The knowledge about then technologies is very meager. The teaching- learning method for ODL is still in conventional style. The infrastructures available at study centre sometimes may not capable to use the audio and audio- visual materials. No technical support staffs were available at study centre for the students for technical help.

ICT integrated pedagogy is the beauty of ODL system. Teacher competency is needed for the tutor in ODL mode. Conventional mode of teaching was not effective in the ODL mode. To be the $21^{\text {st }}$ century teacher, we must familiar with recent trends and new technology.

Hence, the open and distance learning institutions should maintain a comfortable situation, where a learner can access to the various support services that includes audio programmes, audiovisual programmes and finally the internet, through which they can search thousands of information related tot heir subject (Sarma,2011). ICT integration to the related subject area is necessary for the professional development in the field of ODL.

\section{Discussion}

Computer collaboration is the beauty and great opportunity for ODL students (Mathew \& Iloanya, (2016). Moodle is very useful online learning management system for ODL. Students enjoyed with LMS and feeling flexibility on time and space in ODL system. Census method was used in the selection of ODL students. There were only 16 students to study Mathematics and 
English Education in ODL modes. There were not students studying other subjects activated in the selected campuses.

Results of the study indicate that all the students and tutors were very interesting in using ODL mode of learning. Technical risk is the major challenges for the online assessment and final evaluation in this system. Lack of advertising and information, ODL system has not familiar to all the targeted people of Nepal. Experts' opinion was that this system is very useful for disadvantages and special needs people. This system helped to minimize the access and opportunities for the backward people who could not involve in the main stream of face to face mode in the higher education in Nepal.

ODL has the great opportunities for Nepali educators who could not able to involve in the face to face system. Subjective problems can be solving using online mode. Online meeting with tutors and students was the beast strategies for the difficult matters especially in the abstract mathematical expression of Mathematics Education and linguistic problems of English Education.

Regular involvement of online conference/ meeting is useful in ODL system. This will help students' for understanding the difficult matters of each of the subjects and easy to provide the short guidance about the study in ODL mode. This will help to solve the curricular problems as well as technical problems. (Expert/T4)

Experts and tutors argued that the role of online collaboration is very important to get success in ODL mode. Support service helps to solve the ODL problems. Online meeting helps to facilitate the counseling and guidance to the learners. Support service and online classes promotes the online involvement and motivation to the learners.

ODL tutors argued that learning with technology was the cost effective teaching method (Bothan and Mason (2007). Online teaching is easy but the online customization of course materials is very difficult and time consuming. Experts and researches described in the theoretical literature concluded that the customizing the higher mathematical expressions and geometrical configuration were more difficult in the development of online materials.

Providing the equal opportunities and balancing for equity were the major issues and challenge for ODL in the context of Nepal. Providing the computer collaboration and online facilities has seen the challenge for operating the ODL smoothly. Lack of sufficient service provider has seen as another challenge to operationalize the ODL smoothly.

Engagement of tutors to facilitate and regulate learning and to mitigate them any challenges of learning mathematics in this mode is possibly the most critical success factor (Reju 2016). She added that the significant challenges emerged in the Nigerian context, especially within tern et availability and in obtaining adequate and self-explanatory course materials. Availability of internet is also the major problem and challenge in Nepali context. Students frequently have tor each beyond the basic resources provided in their institutions by seeking textbooks and course materials from other ODL institutions. In the finding of this study about the course materials, we 
have to re-customize the ODL materials and needs the pedagogical integration of ODL materials. Poor feedback system was one of the challenges for ODL in Nepal.

According to Kim \& Bonk (2006), technology has played and continues top lay an important role in the development and expansion of online education. The use of technology has enriched the popularity for ODL among learners as it offers flexibility and accessibility. Similarly ODL tutors also found the usage the technology can improve the interaction as well as collaboration among learners. This argument satisfied in the finding of this research. But, the popularization of ODL program is needed to improvement for higher education in Nepal.

Student engagement, interaction and communication using ODL mode are the similar practice as the ODL system in Nepal. These are the benefit of the ODL students. Technological problems and available resources are the challenges of ODL mode in Nepal. The physical resources and infrastructures are not sufficient for ODL programme in Nepal. The study of Mathew \& Iloanya (2016) is more appropriate to support to my research. In this study, I have attempted to identify the opportunities and challenges of ODL program in the context of Nepal. Any on a (2009) focused on his study was on ODL delivery models in Kenya, training and motivation of staff,cost and consistency of the programme delivery across geographical locations, learner's interaction with facilitators and feedback. These are the similar case as the case of ODL system in Nepal. Nepal has the different geographical locations and wide area of remote areas.

Student engagement, online interaction, support services, available functional resources, online facilities, online evaluation system, customization of curriculum and reading materials, skillful tutors flexible completion time duration and standard quality maintenance with face to face program are the major challenges of ODL program in the context of Nepal. Flexible learning time and space, continuity of study with job and other extra activities, online collaboration, online feedback, online assignment, online meeting, online interaction, skill development, low cost educational facilities, worldwide information about the subject matters, easy to teach large numbers of learners, study from remote places are the major opportunities from the ODL program in Nepal.

\section{Conclusion}

Technology usage in ODL teaching and learning avail a lot of benefitted opportunities for both learners and tutors. The benefits accruing from technology usage include improved access, interaction with teachers as well as other students, access to a wide variety of recent and updated resources that are available online as well as contentsharing. It is acknowledged that usage of technology and ODL have a lot of opportunities. There are some challenges faced by both teachers and learners. These are unreliable internet access, technophobia and inadequate pedagogical skills of online teachers. Some of the challenges are academic, some are administrative and some are ICT related challenges in ODL system in Nepal. The use of emerging technologies such as video conferencing, social media, and virtual classrooms and Skype were also recommended by the participants fort he enhancement of ODL offerings. 


\section{Educational Implications}

This research work helps to the policy makers, researchers, teachers, tutors and students concerning about ODL and related subjects. Faculty of Education, Dean Office, and ODEC, TU has attempted to improve the ODL program effectively. This study helps to make plan, policy, strategies and feedback about ODL system. Policy maker can develop the new policy with the help of this report. Tutors and students can be implementing the report of this study in their online teaching and learning. Due to the limited resources, time etc. the researcher could not address all the aspects of this study. Online friendly curriculum; integrating technology, pedagogy and contents for online resources; customizing the textbooks and online friendly resources; development of online library and related materials; empowering for tutors and service providers are more challengeable for the Nepali online learning.

This research concludes that the online educational policy should address about the development of online friendly curriculum, ICT integration in the subject areas, flexibility in the completion courses and number of courses attempted and providing best support-services played an important role in ODL system in Nepal.

\section{References}

Anyona, J. K. (2009). The status and challenges of panendoscopies learning in kenya's public universities (Doctoral dissertation), Kenyatta University.

Botham, R. \& Mason,C.(2007). Good Practice in Enterprise Development in UK Higher Education. Birmingham: National Council for Graduate Entrepreneurship.

Creswell, J. W. (2014). Research design: Qualitative, quantitative and mixed method approaches ( $4^{\text {th }}$ ed.). New Delhi: Sage.

Kim, K.J. \&Bonk, C.J. (2006).The Future of Online Teaching and Learning in Higher Education. Educause Quarterly.

Mathew I. R. \& Iloanya, J. E. (2016). Open and distance learning: Benefits and Challenges of Technology Usage for Online Teaching and Learning in Africa (Doctoral dissertation) Botho University.

Moore, M.M \& Tait, A. (2002).Open and distance learning: Trends, policy and strategy

Neupane, A. (2018a). Use of information and communication technology: A Phenomenological Study on Mathematics Teaching. Shikshya Sandesh, Pokhara: Faculty of Education, Prithvi Narayan Campus, 9 (4), 19-28.

Neupane, A. (2018b). Teachers' experience of teaching with open and distance mode in mathematics education. International Journal of Hydra Research Group (IJHRG): A Multidisciplinary Journal. Kathmandu: Hydra Research center and Policy Center, 1(2), 42-48.

Reju, C.O. (2016). Students' experiences with distance and online learning of universitylevel undergraduate mathematics in Nigeria(Doctoral dissertation), Faculty of Education, University of the Free State. Retrived from,http:/oasis.col.org/bitstream/ $\underline{\text { handle } / 11599 / 2543 / \mathrm{PDF} \text { ?sequence }=4 \& \text { isAllowed }=\mathrm{y}}$ 